\title{
Association of nutraceutical supplements with longer telomere length
}

\author{
DIMITRIS TSOUKALAS ${ }^{1-3^{*}}$, PERSEFONI FRAGKIADAKI ${ }^{2,4^{*}}$, ANCA OANA DOCEA $^{5 *}$, \\ ATHANASIOS K. ALEGAKIS ${ }^{2}$, EVANGELIA SARANDI ${ }^{1,2}$, ELENA VAKONAKI ${ }^{2,4}$, ERALDA SALATAJ ${ }^{6}$, \\ ELISAVET KOUVIDI $^{7}$, DRAGANA NIKITOVIC ${ }^{8}$, LEDA KOVATSI $^{9}$, DEMETRIOS A. SPANDIDOS $^{10}$, \\ ARISTIDIS TSATSAKIS ${ }^{2,4}$ and DANIELA CALINA ${ }^{3}$
}

\begin{abstract}
${ }^{1}$ Metabolomic Medicine Clinic, Health Clinics for Autoimmune and Chronic Diseases, 10674 Athens; ${ }^{2}$ Laboratory of Toxicology, Medical School, University of Crete, 71003 Heraklion, Greece; ${ }^{3}$ Department of Clinical Pharmacy, University of Medicine and Pharmacy, Faculty of Pharmacy, Craiova 200349, Romania; ${ }^{4}$ Spin-Off Toxplus S.A., 71601 Heraklion, Greece; ${ }^{5}$ Department of Toxicology, University of Medicine and Pharmacy, Faculty of Pharmacy, Craiova 200349, Romania; ${ }^{6}$ Institute of Molecular Biology and Biotechnology, Foundation for Research and Technology - Hellas, 70013 Heraklion; ${ }^{7}$ Department of Hematology, University of Crete, School of Medicine; ${ }^{8}$ Laboratory of Anatomy-Histology-Embryology, Medical School, University of Crete, 71003 Heraklion; ${ }^{9}$ Laboratory of Forensic Medicine and Toxicology, School of Medicine, Aristotle University of Thessaloniki, 54124 Thessaloniki;

${ }^{10}$ Laboratory of Clinical Virology, School of Medicine, University of Crete, 71003 Heraklion, Greece
\end{abstract}

Received March 29, 2019; Accepted May 2, 2019

DOI: $10.3892 / \mathrm{ijmm} .2019 .4191$

\begin{abstract}
Telomeres are nucleotide tandem repeats located at the tip of eukaryotic chromosomes that maintain genomic integrity. The gradual shortening of telomeres leads to cellular senescence and apoptosis, a key mechanism of aging and age-related chronic diseases. Epigenetic factors, such as nutrition, exercise and tobacco can affect the rate at which telomeres shorten and can modify the risk of developing chronic diseases. In this study, we evaluated the effects of a combination of nutraceutical supplements (NS) on telomere length (TL) in healthy volunteers with no medical history of any disease. Participants $(n=47)$ were selected from healthy outpatients visiting a private clinic and were divided into the experimental group $(\mathrm{n}=16)$, that received the NS and the control group $(n=31)$. We estimated the length of single
\end{abstract}

Correspondence to: Professor Aristidis Tsatsakis, Laboratory of Toxicology, Medical School, University of Crete, 71003 Heraklion, Greece

E-mail: tsatsaka@uoc.gr

*Contributed equally

Abbreviations: MTL, mean telomere length; CAD, cardiovascular disease; BMI, body mass index; TL, telomere length (of the whole genome); TLS, telomere length of short telomeres (20th percentile); NS, nutraceutical supplements; TLDP, Telomere Length Database Project

Key words: telomere length, nutraceutical supplements, nutrition, telomerase activity, short telomere telomeres in metaphase spread leukocytes, isolated from peripheral blood, using quantitative-fluorescent in situ hybridization (Q-FISH) analysis. The length of the whole telomere genome was significantly increased $(\mathrm{P}<0.05)$ for the mean, 1st quartile and median measurements in the experimental group. Similar findings were observed for short TL (20th percentile) $(\mathrm{P}<0.05)$ for the median and 3rd quartile measurements in the NS group, compared to the control group. The beneficial effects of the supplements on the length of short telomeres remained significant $(\mathrm{P}<0.05)$ following adjustment for age and sex. Telomeres were moderately longer in female patients compared to the male patients. On the whole, the findings of this study suggest that the administration of NS may be linked to sustaining the TL.

\section{Introduction}

Telomeres are DNA regions positioned at the tips of chromosomes. They are composed of repetitive nucleotide sequences (5'-TTAGGG-3'). These functional non-coding repeats protect the ends of eukaryotic chromosomes from attrition and damage. Telomeres shorten during mitotic cell division due to the inability of DNA polymerase to fully replicate the end part of the lagging strand of DNA. This is commonly referred to as the 'end-replication problem'.

Telomere length (TL) gradually decreases, by approximately 20-40 base pairs per year (1). The shortening of telomeres can be reversed by the enzyme telomerase, which is active in high-proliferating cells, such as male germ cells, activated lymphocytes, stem cells and cancer cells $(2,3)$. In most adult human somatic cells though, the expression of telomerase is deficient, and TL decreases with age (1). Telomerase activity has been associated with pregnancy complications $(4,5)$. 
Furthermore, attention has been paid to telomere shortening in various diseases and age-related diseases, such as cancer, cardiovascular diseases (CAD), diabetes, rheumatoid arthritis and psychiatric disorders (6-10). In addition, TL is a biomarker of the replicative past and the replicative potential of somatic cells. Previous studies have focused on the estimation of mean TL (MTL) in age-related diseases $(11,12)$; however, current concepts highlight the pivotal role of critically short telomeres in cell homeostasis (13). Vakonaki et al previously demonstrated an association between TL and drug abuse, which leads to premature biological aging (14). Recently, the creation of a database named 'BIOTEL version 2.4', Telomere Length Database Project (TLDP), was reported (15). This database is a functional semi-automated worksheet that calculates a wide range of TL statistics and is thus a useful tool with applications in research on telomere biology, as well as in biological age estimation (15). It is important to mention that when the length of the telomeres shortens below a threshold limit, cell growth is restricted, and cells undergo cellular senescence or apoptosis (16). Continuous telomere shortening in cells that fail to undergo senescence, leads to critically short telomeres $(<3 \mathrm{~kb})$, prone to chromosome-end fusion. Fused chromosomes break unequally in mitosis, leading to genomic instability and chromosomal rearrangements during cell divisions (17). Indeed, a short telomere load has emerged as a more potent biomarker than MTL or the expression of telomerase $(18,19)$. Actually, recent studies have indicated that a short TL is associated with several age-associated diseases, including CAD, stroke, cancer, arthritis, osteoporosis, cataracts, diabetes type2, hypertension, mental diseases, chronic obstructive pulmonary disease and dementia (9,20-22). Goglin et al suggested that individuals with shorter telomeres have a higher mortality rate, as compared to those with longer telomeres (23). Human studies have shown that TL can be inherited through the direct inheritance of the telomeres and through the specific genetic factors found in the parental gametes (24). Furthermore, telomere shortening can be affected by environmental factors, including physical activity, body mass index (BMI), hormone replacement therapy, smoking, chronic inflammation, oxidative stress, dietary antioxidants and importantly vitamin intake (25-28).

Several studies have examined the correlation of individual nutrients with TL. Indeed, B12 vitamin deficiency has been associated with TL, and an altered DNA methylation (26). In addition, a lack of vitamin B12 and folate can lead to inadequate DNA methylation, genomic instability and telomere shortening (29-31). In a previous study, the beneficial effects of omega-3 (n-3) fatty acids on TL observed in patients with chronic kidney disease, was attributed to reduced oxidative stress (32). Furthermore, it has been shown that omega-3 polyunsaturated fatty acids (PUFAs) can reduce inflammation and decrease oxidative stress (33-35) and thus, protect telomeres from attrition (36). Another study suggested that a shorter TL is associated with a significantly increased risk for breast cancer in pre-menopausal women and women with a lower dietary and supplemental $\beta$-carotene vitamin $\mathrm{C}$ or $\mathrm{E}$ intake (37). In vitro experiments have demonstrated that telomere shortening is delayed by ascorbic acid or its derivatives (38-40) and the lifespan of certain somatic cells has been shown to be increased by $\alpha$-tocophenol (41). To date, TL has been associated with single vitamin or micronutrient intake, while little is known about the effects of their combination on telomere status. A recent study by Tsoukalas et al indicated that the synergistic effects of nutrients and natural compounds can activate telomerase enzyme in vitro, in human peripheral blood mononuclear cells; human clinical studies with these formulations are required in order to reveal the health benefits of telomerase activation through natural molecules (42). Epidemiological studies have demonstrated that the deficiency of multiple concurrent micronutrients is very common globally and is associated with chronic diseases; these studies stress the need to restore these deficiencies through diet and nutraceutical supplements (NS) $(43,44)$.

The aim of the present study was to analyze the TL profile of a population using a combination of NS and to evaluate the putative effects of supplements on TL, in comparison to a healthy population not receiving any supplements.

\section{Materials and methods}

Materials and reagents. One capsule of My Health (Lumis Research SA) contains the following: Mix Vitamin (ascorbic acid, vitamin $\mathrm{E}$ acetate $50 \%$ natural, niacin, vitamin $\mathrm{B} 1$, vitamin K2 Mena Q7 $0.2 \%$, vitamin B6, $\beta$-carotene, vitamin B12 1\%), anti-caking agents (microcrystalline cellulose, mono- and diglycerides of fatty acids, magnesium stearate and silica dioxide. One drop of vitamin D (Pure D3, Natural Doctor) contains 2,000 IU vitamin D. One capsule of Complete D3\&K2 Cofactors (Natural Doctor) contains 2,000 IU vitamin D3, $100 \mu \mathrm{g} \mathrm{K} 2$ and $56 \mathrm{mg}$ magnesium. Two capsules of Omega 3-6-9 (Lumis Research SA) contain the following: $740 \mathrm{mg}$ fish oil, $740 \mathrm{mg}$ linseed oil, $740 \mathrm{mg}$ borage oil (Borrgo officinalis L.), $200 \mathrm{mg}$ Krill oil, $370 \mathrm{mg}$ alpha linolenic acid, 312,6 mg eicosapentaenoic acid (EPA), 154,2 mg docosahexaenoic acid (DHA), 162,8 mg gamma linolenic acid (GLA), $400 \mathrm{mg}$ linoleic acid and 273,8 mg oleic acid. Four capsules of My Antioxidant (Lumis Research SA) contain the following: Mix Vitamin (ascorbic acid, calcium ascorbate, ascorbyl palmitate, natural vitamin $\mathrm{E}$ acetate $50 \%$, vitamin $\mathrm{B} 3$, vitamin $\mathrm{B} 12$ $1 \%, \beta$-carotene, vitamin B5, vitamin B6, vitamin B2, vitamin B1, folic acid, vitamin D3 biotin), One capsule of My Probiotics (Lumis Research SA) contains the following: Lyophilized kefir grains, Lactobacillus casei (LMG-S27763), Lactobscillus reuteri (LMG S-27759), Bifidobacterium bifidum (B. bifidum; LMG S-27761), Lactobacillus acidophilus (LMG S-27762), inulin, acacia fiber and hydroxypropyl cellulose. One scoop of My Gastro (Lumis Research SA) contains the following: 2,500 mg L-glutamine (Kyowa ${ }^{\circledR}$ ) and $500 \mathrm{mg}$ oligo fructose (FOS). One capsule of My Ubiquinol (Q10) (Lumis Research SA) contains $50 \mathrm{mg}$ of ubiquinol.

Study design. The process of TL estimation is depicted in Fig. 1. The participants were selected from individuals visiting a private clinic in Athens for routine checkup, as well as from personnel of the University Hospital of Heraklion. Basic demographic data and a medical history of chronic diseases were obtained. Demographic data included the name, surname, date of birth and sex. Medical history included all the self-reported statements for chronic diseases, such as diabetes, cancer, rheumatoid arthritis, etc., possible exposure to pesticides (occupational) and use of antidepressant medica- 


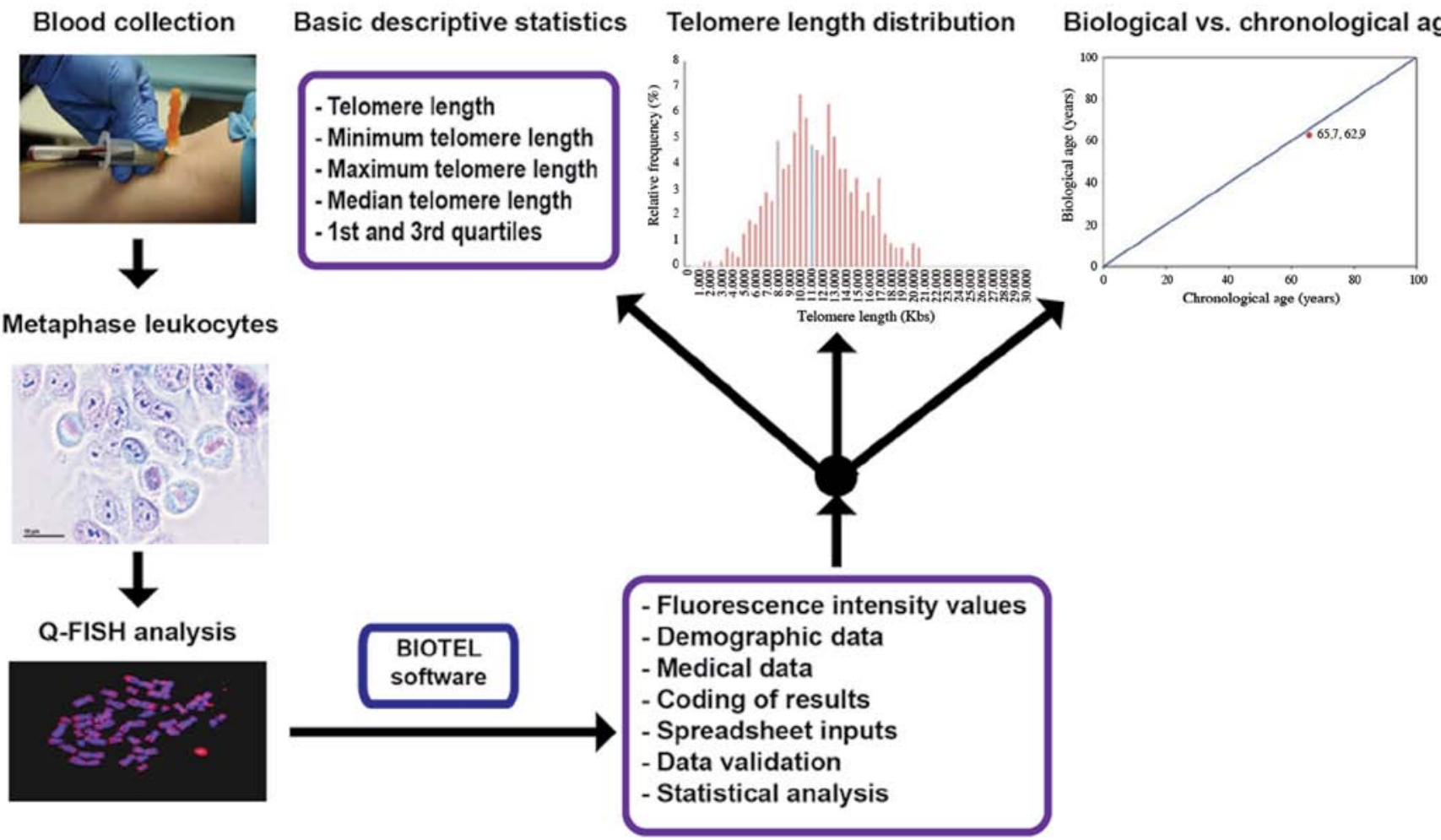

Figure 1. An overview diagram of the telomere estimation process. Fluorescence intensity values as measured using Q-FISH analysis on metaphase leukocytes, following human blood collection were further analyzed with the BIOTEL spreadsheet. Estimation of statistical measures, graphical representations and data nomograms are provided.

tion. Individuals that reported having a medical history of any chronic disease were excluded. Based on these criteria, 47 individuals were selected for the study. They had never taken any supplements prior to the study and they were in the 40-55 age group. The participants were healthy and were not on a restricted diet. They were divided into 2 groups as follows: An experimental group that consisted of 16 individuals supplemented with NS and the control group with 31 individuals that did not receive any supplements. The daily dose of all supplements was assigned according to the suggestions of the manufacturers. Blood samples were collected from all individuals and citrate was used as an anticoagulant. The supplementation period for all participants lasted for 6 to 12 months. The protocol of this study was approved by the Ethics Committee for Patients and Biological Material of the University of Crete with reference no. 63/22.03.2019. Biological Material and information of patients were obtained with written informed consent according to the EU General Data Protection Regulation (GDPR). All procedures performed in studies involving human participants were under the ethical standards with the 1964 Helsinki declaration and its later amendments, or comparable ethical standards.

Quantitative-fluorescent in situ hybridization (Q-FISH) analysis. Peripheral blood samples $(2.5 \mathrm{ml})$ were collected from all participants. Heparinized blood was cultured in RPMI-1640 culture medium supplemented with $10 \%$ fetal bovine serum, $1 \%$ L-glutamine, $1 \%$ penicillin and streptomycin (all from Sigma-Aldrich) and stimulated for $72 \mathrm{~h}$ in a $\mathrm{CO}_{2}$ incubator with phytohemagglutinin. For metaphase chromosome preparations, $10 \mu \mathrm{g} / \mathrm{ml}$ colcemid was added to each culture
$2 \mathrm{~h}$ before harvesting, followed by $\mathrm{KCl}$ hypotonic shock and methanol/acetic (3:1) fixation. Q-FISH analysis on metaphases was performed as previously described $(14,15)$.

Images were captured for each slide, using a $63 \mathrm{X}$ objective and a charge-coupled device camera at 1,024x1,024 pixels resolution and 8-bit depth. For each slide, $>10$ different scanned images were obtained from 3 independent biological replicates. Maximum projections and deconvolution of the images were performed using Leica Q-FISH software [Leica Application Suite-Advanced Fluorescence (LAS-AF) version 3.1.3 for Leica TCS SP8] and telomere fluorescence intensity was analysed using ImageJ (https://imagej.nih.gov/ $\mathrm{ij} /$ ) by two independent investigators. Telomere fluorescence values were converted into kb by using L5178Y-S cells (cat. no. 93050408; Culture Collections, Public Health England) with a stable and known TL, which was estimated to be approximately $7 \mathrm{~kb}(45)$.

Statistical analysis. Percentiles of TL (of the whole telomere genome) and the TL of short telomeres (TLS) (TL <20th percentile) were estimated. The examination of TL and TLS normality was assessed using Kolmogorov-Smirnov's test with Liliefors correction. Differences in proportions were examined using Pearson's Chi-square test or Fisher's exact test when assumptions were not reached. Age comparison was tested using an independent samples t-test. Multiple linear regressions were applied for examining the effect of NS on TL and TLS length following adjustment for age and sex. Box and Whisker plot and bar-charts were used for data graphical representation. IBM SPSS Statistics 23.0 software was used for data analysis and a level of acceptance of null hypothesis was set at $\mathrm{P}=0.05$. 
Table I. Demographic characteristics of the participants in the nutraceutical supplements group (NSG) and control group (CG).

\begin{tabular}{|c|c|c|c|c|c|c|}
\hline & \multicolumn{2}{|c|}{ NSG $(n=16)$} & \multicolumn{2}{|c|}{$\mathrm{CG}(\mathrm{n}=31)$} & Total & P-value \\
\hline Male & 9 & $37.5 \%$ & 15 & $62.5 \%$ & 24 & 0.609 \\
\hline Female & 7 & $30.4 \%$ & 16 & $69.6 \%$ & 23 & \\
\hline Age, years $(\text { means } \pm S D)^{b}$ & 46.4 & 3.5 & 47.6 & 4.0 & $47.1(3.8)$ & 0.323 \\
\hline \multicolumn{7}{|l|}{ Age groups, $(\mathrm{n}, \%)^{\mathrm{c}}$} \\
\hline $40-45$ & 6 & $42.9 \%$ & 8 & $57.1 \%$ & 14 & 0.505 \\
\hline $45-50$ & 8 & $34.8 \%$ & 15 & $65.2 \%$ & 23 & \\
\hline $50-55$ & 2 & $20.0 \%$ & 8 & $80.0 \%$ & 10 & \\
\hline
\end{tabular}

Data were analyzed using aPearson's Chi-square test; ${ }^{\mathrm{b}}$ an independent samples t-test; or $^{\mathrm{c}}$ Fisher's exact test.

Table II. Comparison of whole telomere genome (TL) and short telomere length (TLS) (<20th percentile) (in bases) between the sexes.

\begin{tabular}{lrrrrrr}
\hline & \multicolumn{4}{c}{ Sex } \\
\cline { 2 - 3 } & \multicolumn{2}{c}{ Male (n=24) } & \multicolumn{2}{c}{ Female (n=23) } & \\
\cline { 2 - 3 } & Mean & SD & & Mean & SD & P-value \\
\hline TL $^{\text {a }}$ & & & & & \\
1st Quartile & 8,444 & 1,296 & & 8,692 & 1,374 & 0,528 \\
Median & 10,142 & 1,315 & 10,490 & 1,537 & 0,407 \\
3rd Quartile & 12,107 & 1,505 & & 12,582 & 1,910 & 0,348 \\
TLS & & & & & \\
1st Quartile & 6,321 & 1,288 & 6,516 & 1,079 & 0,577 \\
Median & 7,052 & 1,270 & 7,247 & 1,173 & 0,587 \\
3rd Quartile & 7,592 & 1,283 & 7,792 & 1,293 & 0,598 \\
\hline
\end{tabular}

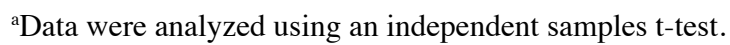

\section{Results}

The demographic characteristics of the participants in the control group (CG) and NS group (NSG) are presented in Table I. The sex distribution between the 2 groups did not differ significantly $(\mathrm{P}=0.609)$, with a similar proportion of males in both the NSG $(n=9,37.5 \%)$ and the CG $(n=15,62.5 \%)$. Age distribution, after dividing the population to 5-year interval groups, revealed that the 2 groups were age-matched $(\mathrm{P}=0.505)$. To elucidate whether demographics had any effect on TL, we performed statistical analysis in both groups with respect to sex. A separate analysis was performed in the respective age groups. As shown in Table II, females had a longer TL compared to males with a difference of 248 to 474 bases in TL and a difference of 195 to 200 bases in TLS. These differences however, did not reach statistical significance, as none of the quartiles in whole or in short telomeres exhibited a statistically significant difference between the 2 sexes $(\mathrm{P}>0.300)$.

TL (of the whole telomere genome) and TLS $(<20$ th percentile) was estimated in the participants of both groups.
Differences in TL and TLS between the NSG and CG are shown in Figs. 2 and 3. Quartiles of TL and TLS were estimated from raw data for each patient separately. There was a statistically significant difference $(\mathrm{P}<0.05)$ in the TL values of the NSG group, compared to the $\mathrm{CG}$, with increased mean quartiles values for the 1 st and 2 nd quartile (median). TL measurements were 844 and 953 bases higher in the NSG group compared to the CG. Accordingly, there were statistically significant increased values of TLS in the 2nd (median) and 3rd quartile with values of $\mathrm{P}=0.044$ and $\mathrm{P}=0.033$, respectively. A tendency for difference was found for the 1st quartile comparisons $(\mathrm{P}=0.051)$.

The position of NSG and CG in the nomograms produced from TLDP data (13) is shown in Fig. 4. Lines of 1st, 2nd (median) and 3rd quartile of TL vs. age were presented, showing the age decrement. Mean age with 2SD of age and TL with $2 \mathrm{SD}$ of both groups were placed onto the diagram. It is clear that the mean TL levels of the NSG are over the line of the median of a healthy population, while the mean TL levels of the CG are under the line of the median of a healthy population. A difference of approximately 1,000 bases was observed.

Furthermore, as demonstrated in Fig. 5, and in more details in Table SI, there were no significant differences in TL among the age groups examined $(\mathrm{P}>0.500)$. P-values of TL vs. age were 0.964 for the 1 st quartile, 0.908 for the median and 0.537 for the 3rd quartile, while P-values for TLS vs. age were 0.741 for the 1st quartile, 0.826 for the median and 0.912 for the $3 \mathrm{rd}$ quartile.

Multiple linear regression models were applied for mean TL (or TLS) and their quartiles were set as dependent variables. Explanatory variables were NSG, age and sex of participants. The results of each regression model are presented in Fig. 6. There was a positive effect for mean TL (beta: 918; 95\% CI: 38-1799), for the 1st quartile TL (beta: 889 ; 95\% CI: 65-1714), for the median TL (beta: 1004; 95\% CI: 125-1883), but not for the 3rd quartile TL (beta: 953; 95\% CI: -128-2035) in the NSG. There was also a positive effect on the median TLS (beta: 0.728 ; 95\% CI: 1-1521) and 3rd quartile TLS (beta: 842; 95\% CI: 45-1639), and tendencies for an effect were observed in the mean TLS $(\mathrm{P}=0.051)$ and in 1st quartile TLS $(\mathrm{P}=0.060)$. Furthermore, Fig. 6 shows the effect (beta coefficients) as derived from multiple linear regression, following adjustment for age and sex (beta and 95\% CI). 


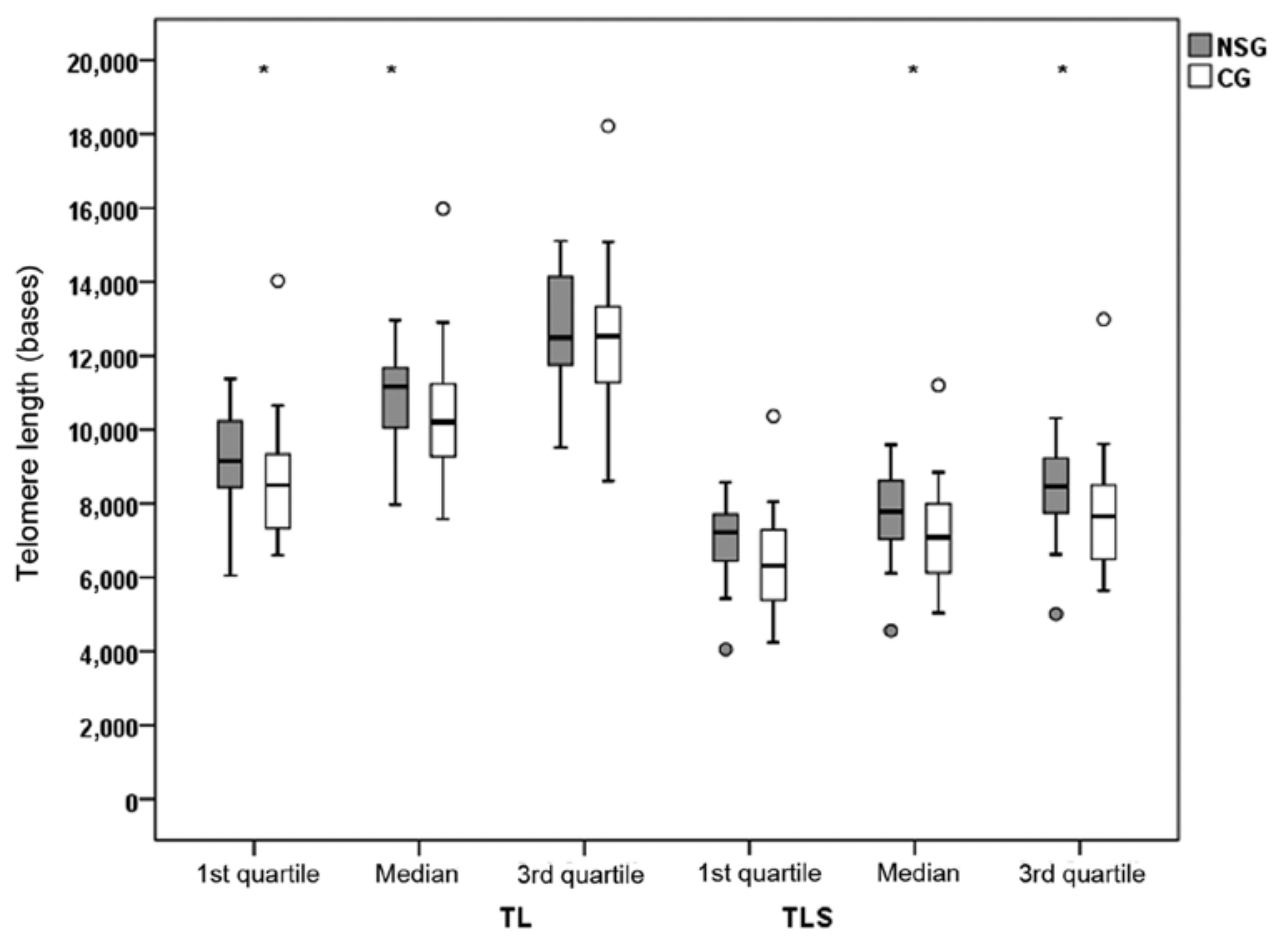

Figure 2. Telomere length values (bases) for the whole telomere genome (TL) and the short telomeres (TLS) (<20th percentile) in the nutraceutical supplements group (NSG) and the control group (CG). Asterisks $\left(^{*}\right)$ indicate a significant difference of $\mathrm{P}<0.05$ between the groups, resulting from linear regression analysis following adjustment for age and sex.

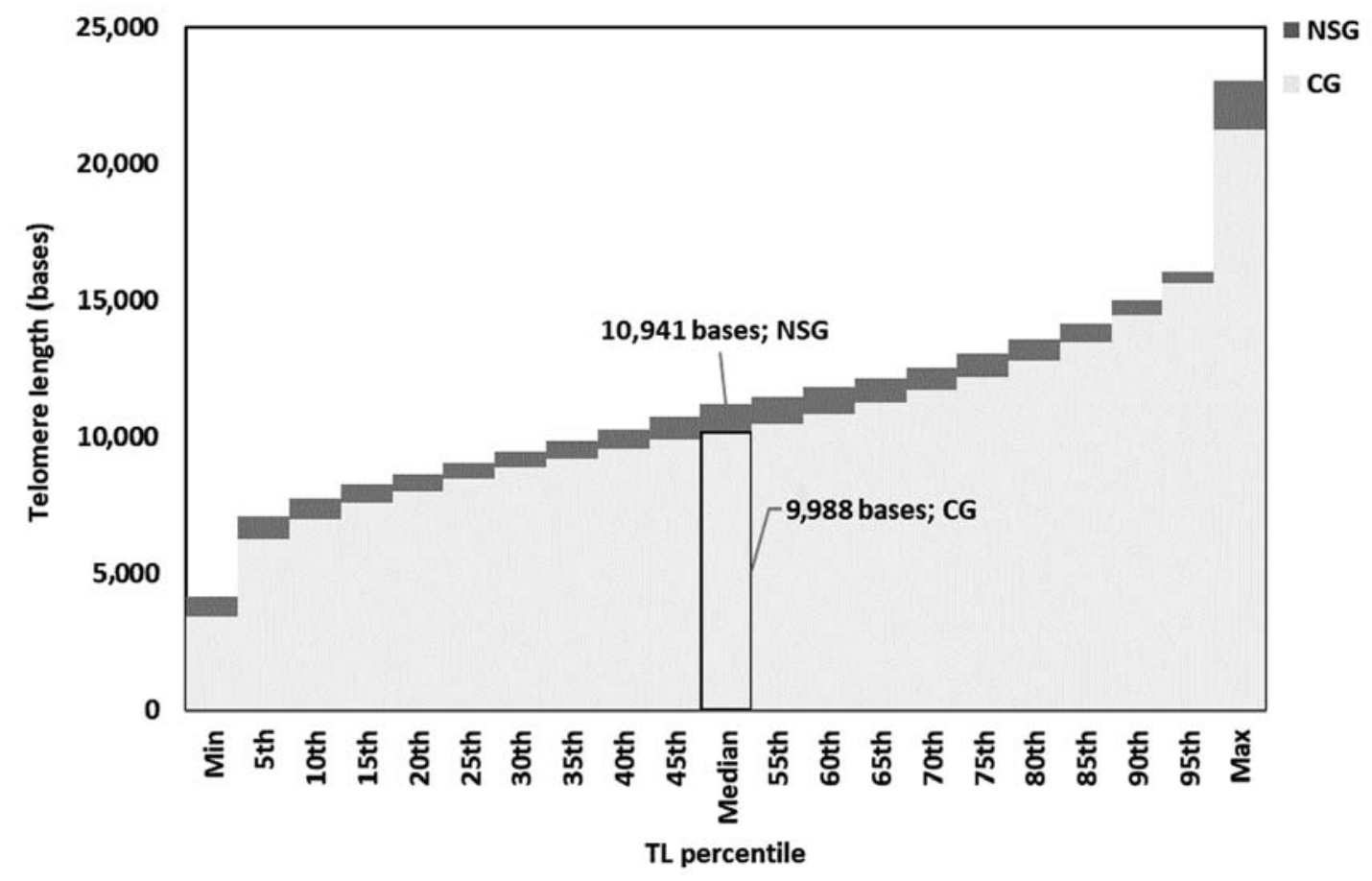

Figure 3. Stacked bar chart of grouped median telomere lengths (in bases) of the control group (CG; light grey) and nutraceutical supplements group (NSG; dark grey). Each bar corresponds to a 5\% increment in the grouped median telomere length. NSG group values tended to be higher in all studied percentiles than the CG group. TL, telomere length.

\section{Discussion}

The results of the present study suggest that the daily administration of NS favorably affects the length of whole and short telomeres, independent of sex and age. Although the underlying mechanisms of the effects of NS remain unclear, their effects on several key mechanisms, including oxidative stress and chronic inflammation, could be linked to TL maintenance (46). Indeed, studies have demonstrated that increased oxidative stress and inflammation are associated with a reduced 


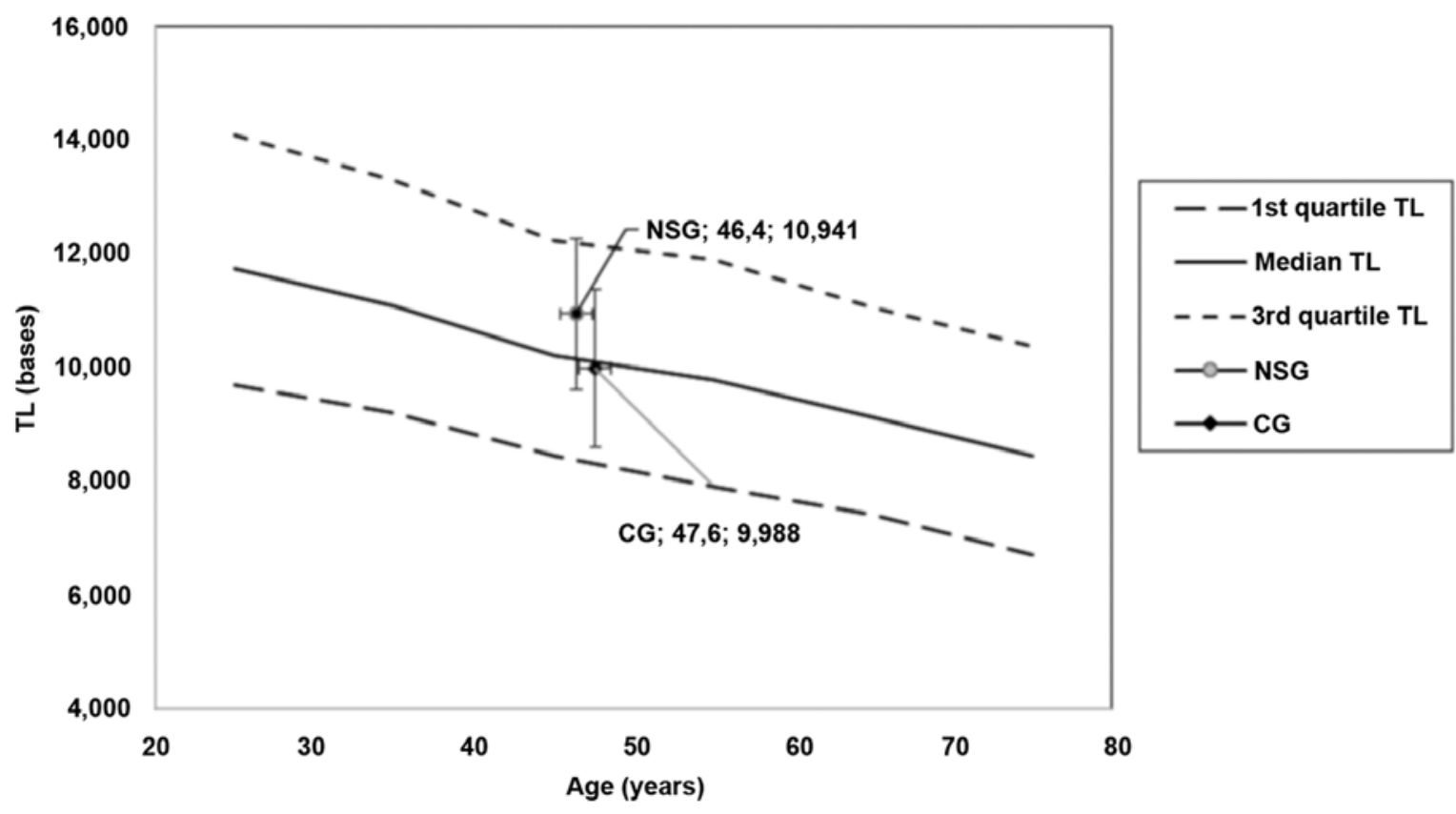

Figure 4. Position of median TL in the nutraceutical supplements group (NSG) and control group (CG) in the nomograms of TL vs. age. On each pair of numbers located in chart, first number refers to age in years, second number refers to TL in kb. Error bars refer to age and TL dispersion (2x standard deviation). TL, telomere length.

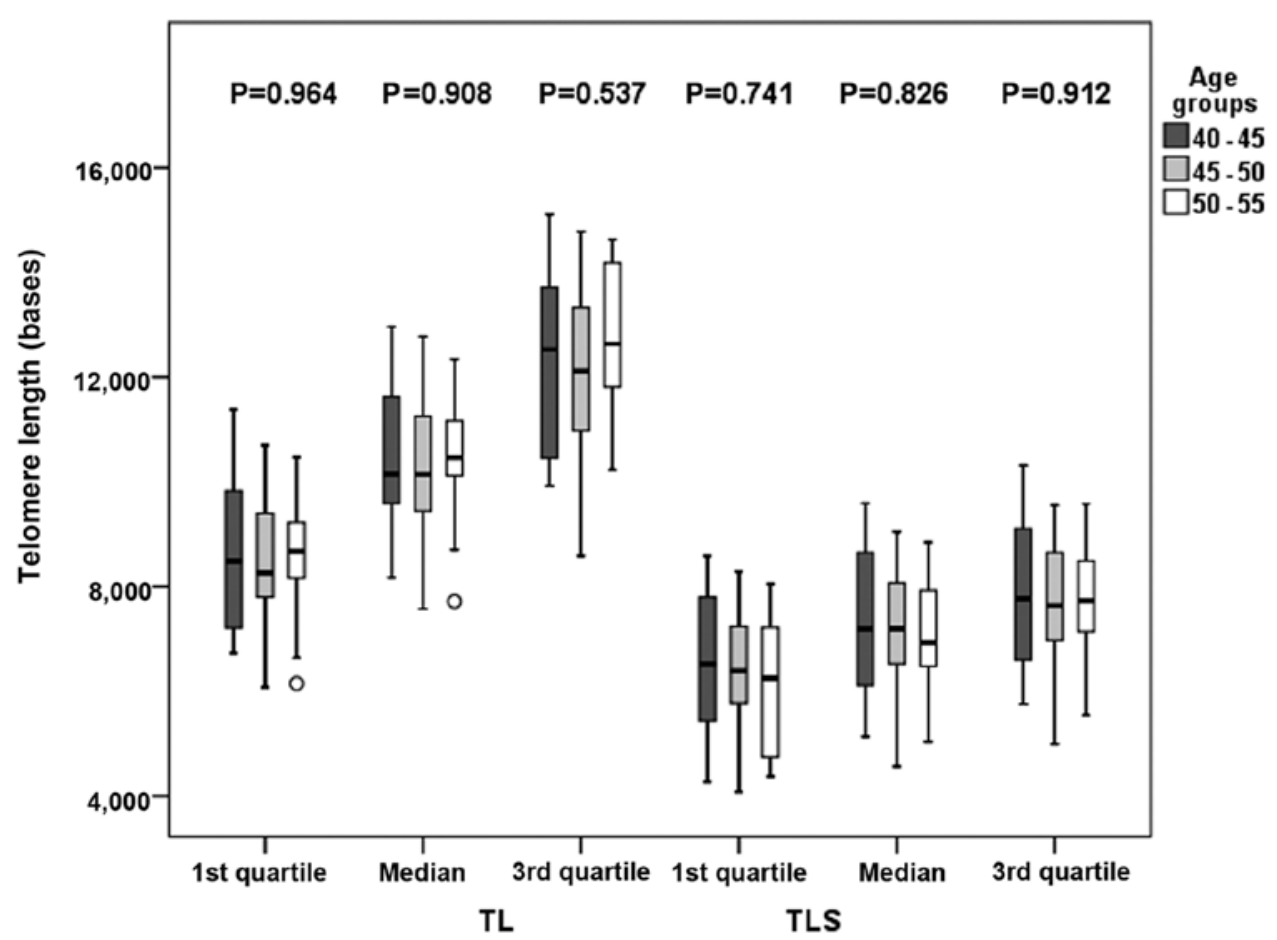

Figure 5. Box plots graphs of TL and TLS among age groups using quartiles as length indicators from all data [control group (CG) and nutraceutical supplements group (NSG)]. The $\circ$ symbol indicates an outlier. Asterisks $\left({ }^{*}\right)$ indicate a significant difference of $\mathrm{P}<0.05$ between the groups, resulting from linear regression analysis following adjustment for sex and nutrient supplements groups. TL, telomere length; TLS, short telomere length.

leukocyte TL in patients with periodontitis (47), as well as in patients with Parkinson's disease (48). Furthermore, Ma et al reported that older individuals with central obesity, hyperglycemia, insulin resistance and lower antioxidant levels had a shorter leukocyte TL; specifically, the authors demonstrated that a decreased TL correlated with increased oxidative stress in patients with type 1 and type 2 diabetes (49). Furthermore, oxidative stress has been linked to TL shortening during aging, in a comparative study that concluded that elderly males living in Greece have lower indices of oxidative stress and higher antioxidant levels, compared to a corresponding population of elderly Dutch males (50). The authors suggested that the length of telomeres in leukocytes was significantly greater in the Greek compared to the Dutch population, as 
TL (bases) TLS (bases)

3rd

Mean 1st quartile Median quartile

Mean 1st quartile Median

3rd

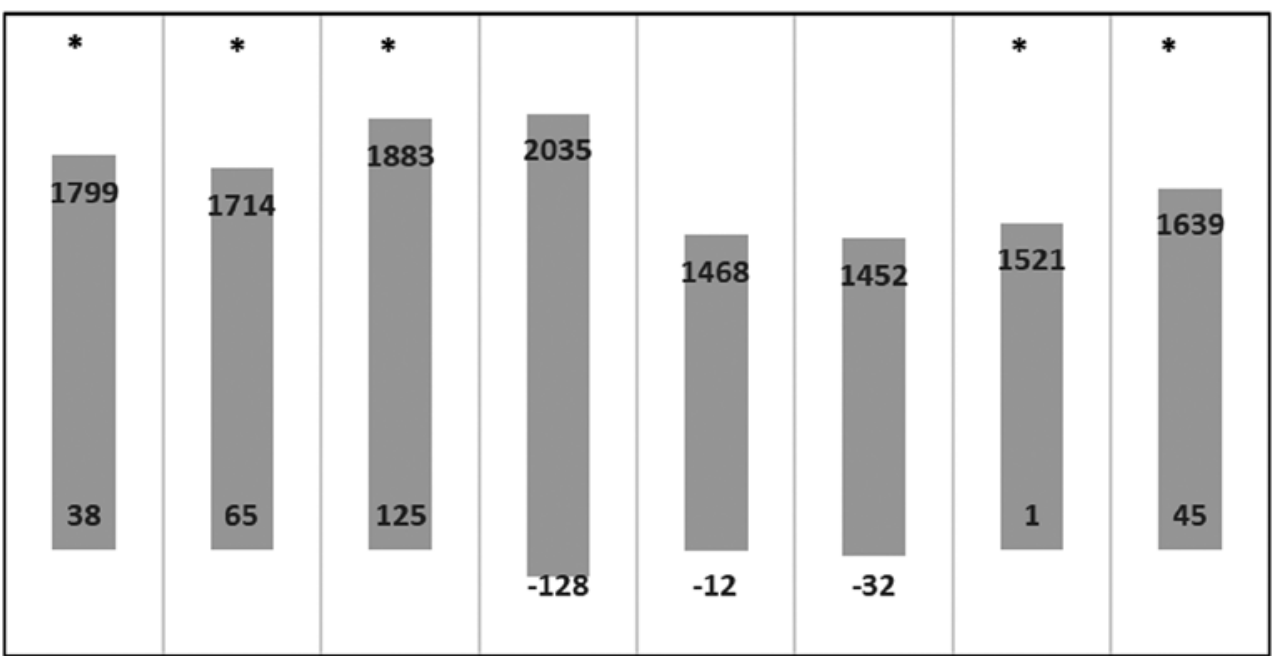

Figure 6. 95\% confidence intervals of beta's as derived from linear regression models of TL or TLS vs. nutraceutical supplements group of adjustment of age and sex. Asterisks $(*)$ indicate a valid model (effect) of nutraceutical supplements group to TL or TLS measure. TL, telomere length; TLS, short telomere length.

the latter live in a more stressful urban setting and follow a diet poor in antioxidant nutrients. Indeed, antioxidants and anti-inflammatory agents have been shown to reduce the pace of TL shortening (51). In a previous study, Paul associated the availability of vitamin B and D with leukocyte (LTL) (52). Furthermore, in that study, serum folate and its metabolites were positively associated with LTL. It has been suggested that the mechanisms through which these nutritional factors attenuate telomere attrition are antioxidant activity, DNA methylation and the prevention of DNA damage (53). In addition, it has been indicated that carotenoids, omega-3-fatty acid, coenzyme Q10, selenium and vitamin D can reduce the rate of telomeric shortening (51). In 2013, Kiecolt-Glaser et al demonstrated that men and women aged 40-85 years who had been taking supplementation, including omega-3 fatty acids, had reduced oxidative stress and an increased TL (54).

In this study, we present findings from the evaluation of TL in participants receiving a combination of vitamin supplements. An advantage of the present study is the methodology of TL measurement. We measured the TL of peripheral blood leukocytes using a method of high sensitivity (Q-FISH) to produce data on TL and TLS ( $<20$ th percentile) percentages using BIOTEL (15). We determined a statistically significant increase in TLS and TL by NS. This is a very interesting finding, as there is evidence indicating that a short telomere load is more critical to cell homeostasis than MTL, or the expression of telomerase $(18,17)$. The increase of short telomeres, measured as a percentage, predicts longevity in mammals and is reversely associated with the majority of age-related diseases. Although the majority of measurements of TL in leukocyte subpopulations have been performed by flow-FISH or real-time PCR, which gives the average length of short telomeres, Q-FISH provides results on median length of single telomeres, the percentage of short telomeres and provides an overview of the rate of telomere shortening and longevity (13).
In this study, we performed an analysis of the TL and TLS between the 2 sexes and did not find a statistically significant difference between males and females. This finding may be attributed to the relatively small size of the group. A previous study by Herrmann et al suggested that telomeres are longer in women due to higher estrogen levels, which increase telomerase activity and present antioxidant effects (53).

The limitations of this study include the small number of participants, as well as the fact that not all lifestyle parameteres that can affect TL and telomerase activity were determined. Taking this limitation into account, the effects of NS on TL presented herein highlight the need for the further evaluation of the underlying mechanisms.

In conclusion, in this study, we demonstrate that NS may affect the length of short telomeres. Short telomeres are critical to cell homeostasis and the only reliable method for the evaluation of short telomere distribution, to date, is Q-FISH. Therefore, this study provides evidence that the antioxidant effects of NS is implicated in TL maintainance. Future research is required to focus on the mechanisms through which NS affect telomere shortening.

\section{Acknowledgements}

The study is part of the special part of $\mathrm{PhD}$ thesis from University of Medicine and Pharmacy and Craiova. The authors would like to thank all the administrative, technical and medical staff of Toxplus, the Metabolomic Medicine health clinic, and the Laboratory of Toxicology for their dedicated involvement in this study.

\section{Funding}

This study was funded by Metabolomic Medicine S.A. and Toxplus S.A. and supported by the Special Research Account of University of Crete (ELKE nos. 4602, 4920 and 3963). 


\section{Availability of data and materials}

The datasets presented in this study are available from the corresponding author upon reasonable request.

\section{Authors' contributions}

DT, PF, AT, DAS and DC conceived and designed the study and wrote the manuscript. PF, EV and AOD performed the data processing and quality control assessment. EvS, AKA and DN performed the statistical analysis and data interpretation. LK interpreted the data and critically revised the article. EK and ErS performed the imaging analysis. All authors reviewed and approved the manuscript prior to submission and have approved the final manuscript.

\section{Ethics approval and consent to participate}

The protocol of this study was approved by the Ethics Committee for Patients and Biological Material of the University of Crete with reference no. 63/22.03.2019. Biological Material and information of patients were obtained with written informed consent according to the EU General Data Protection Regulation (GDPR). All procedures performed in studies involving human participants were under the ethical standards with the 1964 Helsinki declaration and its later amendments, or comparable ethical standards.

\section{Patient consent for publication}

Not applicable.

\section{Competing interests}

DAS is the Editor-in-Chief for the journal, but had no personal involvement in the reviewing process, or any influence in terms of adjudicating on the final decision, for this article. DT is a scientific advisor for Lumis Research SA and Natural Doctor SA. The other authors declare no competing interests. To avoid any bias in the collection of the experimental data, the experiments were conducted by the Laboratory of Toxicology of the Medical School of the University of Crete. Lumis Research SA and Natural Doctor SA had no involvement in the preparation of the manuscript, the results and the supervision of the study.

\section{References}

1. Starkweather AR, Alhaeeri AA, Montpetit A, Brumelle J, Filler K, Montpetit M, Mohanraj L, Lyon DE and Jackson-Cook CK: An integrative review of factors associated with telomere length and implications for biobehavioral research. Nurs Res 63: 36-50, 2014

2. Blackburn EH, Chan S, Chang J, Fulton TB, Krauskopf A, McEachern M, Prescott J, Roy J, Smith C and Wang H: Molecular manifestations and molecular determinants of telomere capping. Cold Spring Harb Symp Quant Biol 65: 253-263, 2000.

3. Beyne-Rauzy O, Prade-Houdellier N, Demur C, Recher C, Ayel J, Laurent G and Mansat-De Mas V: Tumor necrosis factor-alpha inhibits hTERT gene expression in human myeloid normal and leukemic cells. Blood 106: 3200-3205, 2005.

4. Westin ER, Aykin-Burns N, Buckingham EM, Spitz DR, Goldman FD and Klingelhutz AJ: The p53/p21(WAF/CIP) pathway mediates oxidative stress and senescence in dyskeratosis congenita cells with telomerase insufficiency. Antioxid Redox Signal 14: 985-997, 2011.
5. Fragkiadaki P, Tsoukalas D, Fragkiadoulaki I, Psycharakis C, Nikitovic D, Spandidos DA and Tsatsakis AM: Telomerase activity in pregnancy complications (Review). Mol Med Rep 14: 16-21, 2016

6. Fujii H, Shao L, Colmegna I, Goronzy JJ and Weyand CM: Telomerase insufficiency in rheumatoid arthritis. Proc Natl Acad Sci USA 106: 4360-4365, 2009.

7. VakonakiE, Tsiminikaki K, Plaitis S, Fragkiadaki P, Tsoukalas D, Katsikantami I, Vaki G, Tzatzarakis MN, Spandidos DA and Tsatsakis AM: Common mental disorders and association with telomere length. Biomed Rep 8: 111-116, 2018.

8. Wu X, Amos CI, Zhu Y, Zhao H, Grossman BH, Shay JW, Luo S, Hong WK and Spitz MR: Telomere dysfunction: A potential cancer predisposition factor. J Natl Cancer Inst 95: 1211-1218, 2003.

9. Willeit P, Raschenberger J, Heydon EE, Tsimikas S, Haun M, Mayr A, Weger S, Witztum JL, Butterworth AS, Willeit J, et al: Leucocyte telomere length and risk of type 2 diabetes mellitus: New prospective cohort study and literature-based meta-analysis. PLoS One 9: e112483-e112483, 2014.

10. Calado RT and Young NS: Telomere diseases. N Engl J Med 361: 2353-2365, 2009

11. Turner KJ, Vasu V and Griffin DK: Telomere biology and human phenotype. Cells 8: E73, 2019.

12. Sanders JL and Newman AB: Telomere length in epidemiology: A biomarker of aging, age-related disease, both, or neither? Epidemiol Rev 35: 112-131, 2013.

13. Vera E, Bernardes de Jesus B, Foronda M, Flores JM and Blasco MA: The rate of increase of short telomeres predicts longevity in mammals. Cell Rep 2: 732-737, 2012.

14. Vakonaki E, Tzatzarakis M, Tsiminikaki K, Nathena D, Fragkiadaki P, Kalliantasi K, Kanaki K, Vaki G, Plaitis S, Tsoukalas D, et al: Effect of chronic and heavy drug abuse on biological aging. World Acad Sci 1: 67-73, 2019.

15. Tsatsakis A, Tsoukalas D, Fragkiadaki P, Vakonaki E, Tzatzarakis M, Sarandi E, Nikitovic D, Tsilimidos G and Alegakis AK: Developing BIOTEL: A semi-automated spreadsheet for estimating telomere length and biological age. Front Genet 10: 84, 2019.

16. Shay JW and Wright WE: Hallmarks of telomeres in ageing research. J Pathol 211: 114-123, 2007.

17. Muraki K, Nyhan K, Han L and Murnane JP: Mechanisms of telomere loss and their consequences for chromosome instability. Front Oncol 2: 135, 2012

18. Hemann MT, Strong MA, Hao LY and Greider CW: The shortest telomere, not average telomere length, is critical for cell viability and chromosome stability. Cell 107: 67-77, 2001.

19. Hao LY, Armanios M, Strong MA, Karim B, Feldser DM, Huso D and Greider CW: Short telomeres, even in the presence of telomerase, limit tissue renewal capacity. Cell 123: 1121-1131, 2005.

20. Baltzis D, Meimeti E, Grammatikopoulou MG, Roustit M, Mavrogonatou E, Kletsas D, Efraimidou S, Manes C, Nikolouzakis TK, Tsiaoussis J, et al: Assessment of telomerase activity in leukocytes of type 2 diabetes mellitus patients having or not foot ulcer: Possible correlation with other clinical parameters. Exp Ther Med 15: 3420-3424, 2018.

21. Nikolouzakis TK, Vassilopoulou L, Fragkiadaki P, Mariolis Sapsakos T, Papadakis GZ, Spandidos DA, Tsatsakis AM and Tsiaoussis J: Improving diagnosis, prognosis and prediction by using biomarkers in CRC patients (Review). Oncol Rep 39: 2455-2472, 2018

22. Haycock PC, Heydon EE, Kaptoge S, Butterworth AS, Thompson A and Willeit P: Leucocyte telomere length and risk of cardiovascular disease: Systematic review and meta-analysis. BMJ 349: g4227, 2014.

23. Goglin SE, Farzaneh-Far R, Epel ES, Lin J, Blackburn EH and Whooley MA: Change in leukocyte telomere length predicts mortality in patients with stable coronary heart; disease from the heart and soul study. PLoS One 11: e0160748, 2016.

24. De Meyer T, Vandepitte K, Denil S, De Buyzere ML, RietzschelER and Bekaert S: A non-genetic, epigenetic-like mechanism of telomere length inheritance? Eur J Hum Genet 22: 10-11, 2014.

25. Armanios M: Telomeres and age-related disease: How telomere biology informs clinical paradigms. J Clin Invest 123: 996-1002, 2013.

26. Pusceddu I, Herrmann M, Kirsch SH, Werner C, Hübner U, Bodis M, Laufs U, Wagenpfeil S, Geisel J and Herrmann W: Prospective study of telomere length and LINE-1 methylation in peripheral blood cells: The role of B vitamins supplementation. Eur J Nutr 55: 1863-1873, 2016 
27. Pusceddu I, Herrmann M, Kirsch SH, Werner C, Hübner U, Bodis M, Laufs U, Widmann T, Wagenpfeil S, Geisel J, et al: One-carbon metabolites and telomere length in a prospective and randomized study of B- and/or D-vitamin supplementation. Eur J Nutr 56: 1887-1898, 2017.

28. Richards JB, Valdes AM, Gardner JP, Paximadas D, Kimura M, Nessa A, Lu X, Surdulescu GL, Swaminathan R, Spector TD, et al: Higher serum vitamin D concentrations are associated with longer leukocyte telomere length in women. Am J Clin Nutr 86: 1420-1425, 2007.

29. Moores CJ, Fenech M and O'Callaghan NJ: Telomere dynamics: The influence of folate and DNA methylation. Ann NY Acad Sci 1229: 76-88, 2011.

30. Holick MF: Vitamin D deficiency. N Engl J Med 357: 266-281, 2007.

31. Nazki FH, Sameer AS and Ganaie BA: Folate: Metabolism, genes, polymorphisms and the associated diseases. Gene 533: 11-20, 2014.

32. Barden A, O'Callaghan N, Burke V, Mas E, Beilin LJ, Fenech M, Irish AB, Watts GF, Puddey IB, Huang RC, et al: n-3 fatty acid supplementation and leukocyte telomere length in patients with chronic kidney disease. Nutrients 8: 175, 2016.

33. Calder PC: Polyunsaturated fatty acids and inflammation. Biochem Soc Trans 33: 423-427, 2005.

34. Kiecolt-Glaser JK, Belury MA, Andridge R, Malarkey WB and Glaser R: Omega-3 supplementation lowers inflammation and anxiety in medical students: A randomized controlled trial. Brain Behav Immun 25: 1725-1734, 2011.

35. Nälsén C, Vessby B, Berglund L, Uusitupa M, Hermansen K, RiccardiG, Rivellese A, StorlienL, Erkkilä A, Ylä-Herttuala S, et al: Dietary (n-3) fatty acids reduce plasma F2-isoprostanes but not prostaglandin F2alpha in healthy humans. J Nutr 136: 1222-1228, 2006.

36. Zhang J, Rane G, Dai X, Shanmugam MK, Arfuso F, Samy RP, Lai MK, Kappei D, Kumar AP and Sethi G: Ageing and the telomere connection: An intimate relationship with inflammation. Ageing Res Rev 25: 55-69, 2016.

37. Shen J, Gammon MD, Terry MB, Wang Q, Bradshaw P, Teitelbaum SL, Neugut AI and Santella RM: Telomere length, oxidative damage, antioxidants and breast cancer risk. Int Cancer 124: 1637-1643, 2009.

38. Furumoto K, Inoue E, Nagao N, Hiyama E and Miwa N: Age-dependent telomere shortening is slowed down by enrichment of intracellular vitamin C via suppression of oxidative stress. Life Sci 63: 935-948, 1998.

39. Yokoo S, Furumoto K, Hiyama E and Miwa N: Slow-down of age-dependent telomere shortening is executed in human skin keratinocytes by hormesis-like-effects of trace hydrogen peroxide or by anti-oxidative effects of pro-vitamin C in common concurrently with reduction of intracellular oxidative stress. J Cell Biochem 93: 588-597, 2004.

40. Kashino G, Kodama S, Nakayama Y, Suzuki K, Fukase K, Goto $\mathrm{M}$ and Watanabe M: Relief of oxidative stress by ascorbic acid delays cellular senescence of normal human and Werner syndrome fibroblast cells. Free Radic Biol Med 35: 438-443, 2003.

41. Tanaka Y, Moritoh Y and Miwa N: Age-dependent telomereshortening is repressed by phosphorylated alpha-tocopherol together with cellular longevity and intracellular oxidative-stress reduction in human brain microvascular endotheliocytes. J Cell Biochem 102: 689-703, 2007.
42. Tsoukalas D, Fragkiadaki P, Docea AO, Alegakis AK, Sarandi E, Spandidos DA, Tsatsakis A, Razgonova MP and Calina D: Discovering novel telomerase activators. Mol Med Rep (In press).

43. Bailey RL, West KP Jr and Black RE: The epidemiology of global micronutrient deficiencies. Ann Nutr Metab 66 (Suppl 2): 22-33, 2015

44. Fairfield KM and Fletcher RH: Vitamins for chronic disease prevention in adults: Scientific review. JAMA 287: 3116-3126, 2002.

45. McIlrath J, Bouffler SD, Samper E, Cuthbert A, Wojcik A, Szumiel I, Bryant PE, Riches AC, Thompson A, Blasco MA, et al: Telomere length abnormalities in mammalian radiosensitive cells. Cancer Res 61: 912-915, 2001.

46. Lindqvist D, Epel ES, Mellon SH, Penninx BW, Révész D, Verhoeven JE, Reus VI, Lin J, Mahan L, Hough CM, et al: Psychiatric disorders and leukocyte telomere length: Underlying mechanisms linking mental illness with cellular aging. Neurosci Biobehav Rev 55: 333-364, 2015.

47. Masi S, Salpea KD, Li K, Parkar M, Nibali L, Donos N, Patel K, Taddei S, Deanfield JE, D'Aiuto F, et al: Oxidative stress, chronic inflammation, and telomere length in patients with periodontitis. Free Radic Biol Med 50: 730-735, 2011.

48. Watfa G, Dragonas C, Brosche T, Dittrich R, Sieber CC, Alecu C, Benetos A and Nzietchueng R: Study of telomere length and different markers of oxidative stress in patients with Parkinson's disease. J Nutr Health Aging 15: 277-281, 2011.

49. Ma D, Zhu W, Hu S, Yu X and Yang Y: Association between oxidative stress and telomere length in Type 1 and Type 2 diabetic patients. J Endocrinol Invest 36: 1032-1037, 2013.

50. de Vos-Houben JM, Ottenheim NR, Kafatos A, Buijsse B, Hageman GJ, Kromhout D and Giltay EJ: Telomere length, oxidative stress, and antioxidant status in elderly men in Zutphen and Crete. Mech Ageing Dev 133: 373-377, 2012.

51. Prasad KN, Wu M and Bondy SC: Telomere shortening during aging: Attenuation by antioxidants and anti-inflammatory agents Mech Ageing Dev 164: 61-66, 2017.

52. Paul L: Diet, nutrition and telomere length. J Nutr Biochem 22 895-901, 2011.

53. Herrmann M, Pusceddu I, Marz W and Herrmann W: Telomere biology and age-related diseases. Clin Chem Lab Med 56 1210-1222, 2018

54. Kiecolt-Glaser JK, Epel ES, Belury MA, Andridge R, Lin J, Glaser R, Malarkey WB, Hwang BS and Blackburn E: Omega-3 fatty acids, oxidative stress, and leukocyte telomere length: A randomized controlled trial. Brain Behav Immun 28: 16-24, 2013.

This work is licensed under a Creative Commons Attribution-NonCommercial-NoDerivatives 4.0 International (CC BY-NC-ND 4.0) License. 